\title{
Institutions and governments can slow climate change by regulating and reducing halocarbon refrigerant use
}

\author{
Martin Wolf ${ }^{1, *}$, Adam Meier $^{2}$, Bridget Nyland ${ }^{3}$, Sejong Youn ${ }^{4}$, Debra Stump ${ }^{4}$, and Wendy Jacobs ${ }^{4,5}$ \\ Edited by Kindle Williams and Anthony Tabet
}

\section{HIGHLIGHTS}

- Halocarbon refrigerants are manufactured chemicals used extensively in air conditioning, chilled water, and refrigeration equipment. There are serious environmental implications to continued halocarbon refrigerant use.

- There are gaps in federal regulation of halocarbon refrigerant use. This leaves room for state, local, and voluntary policies to reduce halocarbon use and emissions.

- Halocarbon refrigerant emissions can occur throughout the lifespan of refrigerant-containing equipment: during installation, use, and during/following retirement. Compiling inventories of refrigerants can help institutions reduce use and emissions of halocarbon refrigerants. Pilot projects can demonstrate effective alternatives to commonly used HFCs/halocarbons, some of which can achieve efficiency gains. These proofs-of-concept and possible financial savings resulting from their implementation can help institutions and governments overcome technical, social, and political barriers to reducing the climatic impact of their refrigerant use.

Halocarbon refrigerant emissions are the fastest-growing source of greenhouse gas emissions around the globe. The continued use of these refrigerants poses serious environmental threats. In the absence of strong federal regulation on halocarbon use, state and local governments and institutions can commit to reducing halocarbon refrigerant emissions. Here, we outline policies that

\footnotetext{
${ }^{1}$ Department of Earth, Atmospheric, and Planetary Sciences, Massachusetts Institute of Technology, Cambridge, MA

${ }^{2}$ Harvard T.H. Chan School of Public Health, Harvard University, Boston, MA

${ }^{3}$ Harvard Business School, Harvard University, Boston, MA

${ }^{4}$ Harvard Law School, Harvard University, Cambridge, MA

${ }^{5}$ Emmett Environmental Law \& Policy Clinic, Harvard Law School, Harvard University, Cambridge, MA

*Email: mjwolf@mit.edu
}

The authors declare no conflict of interest.

(c) 2020 The Author(s) governments and users of these refrigerants can adopt to minimize their emissions. These policies include cataloging and maintaining their climate control equipment and committing to alternative refrigerants with lesser environmental impacts.

W alocarbon refrigerants are manufactured chemicals used pervasively in air conditioning, chilled water, and refrigeration equipment. The continued use and emission of these chemicals poses serious environmental risks. This article discusses the impacts of halocarbon refrigerant emissions, challenges to mitigating halocarbon use, and opportunities governments and institutions can harness when implementing policies to reduce reliance on halocarbon refrigerants in climate-control equipment. Policies to reduce refrigerant emissions require transnational collaboration. U.S. industries, institutions, and policymakers are uniquely positioned to adopt and advance greener alternatives. The United States should therefore coordinate and lead international efforts to adopt next-generation refrigerants.

There are four categories of halocarbon refrigerants, including halons, chlorofluorocarbons (CFCs), hydrochlorofluorocarbons (HCFCs), and hydrofluorocarbons (HFCs). Halons, CFCs, and HCFCs are known to deplete radiation-shielding ozone in the Earth's stratosphere[1], increasing the prevalence of skin cancer[2]. The ozone-depletion potential of HFCs is minimal. Like CFCs, HCFCs, and halons, however, HFCs are potent greenhouse gases with 100 to 10,000 times the warming potential of carbon dioxide[3]. The most commonly used HFCs in refrigeration and air conditioning applications include pure compounds like R134a and blends like R410a. Refrigerant emissions constitute the fastest growing source of greenhouse gases in much of the world. U.S. emissions alone have increased $248 \%$ in the last three decades[4]. Total halocarbon refrigerant emissions are responsible for $14 \%$ of measured global warming in the industrial era[3]. CFCs and HCFCs account for the majority of this warming. Although CFC and HCFC production is now banned, legal use and unlawful production of these refrigerants continue to present climatic threats[5,6]. HFC emissions currently account for less than $1 \%$ of warming. However, unabated 
HFC emissions could cause an additional $0.1 \mathrm{C}$ of global temperature increase by 2050 and $0.5 \mathrm{C}$ by 2100 . This could equal up to $12 \%$ of the warming induced by carbon dioxide emissions over the same time period[7]. Moreover, continued HFC emissions could lead to $9 \mathrm{~cm}$ of sea level rise by 2100 [8]. Some of these environmental impacts will persist for thousands of years after halocarbon refrigerant emissions cease due to the prolonged exchange of heat between the ocean and the atmosphere[9].

Widespread reductions in halocarbon refrigerant emissions are therefore necessary to mitigate considerable environmental harm in the coming decades. Alternatives to halocarbon refrigerants include hydrofluoroolefins (HFOs) and so-called "natural refrigerants" such as carbon dioxide, ammonia, and propane. These compounds have greatly-reduced global warming potentials relative to previous halocarbon refrigerants and are feasible alternatives to HFCs in many mobile, residential, and commercial air conditioning and refrigeration applications. Passive cooling options, such as shading or increased ventilation, can also reduce the demand for refrigerant use in many circumstances.

Refrigerant emissions occur throughout the lifecycle of cooling equipment (Figure 1). These stages include (1) refrigerant production and initial charging of equipment, (2) equipment operation, and (3) equipment disposal. While the majority of emissions occur during operation and disposal, policies can target halocarbon refrigerant emissions reduction at each stage of the lifecycle[10,11]. Figure 1 illustrates the best practices governments and institutions can adopt to reduce halocarbon refrigerant emissions. These policies encompass two strategies. First, existing infrastructure's leaks can be minimized to reduce refrigerant emissions during equipment operation. Second, governments and institutions can reduce halocarbon refrigerant emissions by minimizing their use. We discuss here key challenges and opportunities of both approaches, outlining the best practices and regulations that institutions can adopt to mitigate emissions.

\section{Regulatory Challenges and Opportunities}

\section{Unpredictable Federal Regulatory Landscape}

Refrigerant regulations are shaped by international treaties to ban halocarbon refrigerant use. The Montreal Protocol of 1987 established a global phase-out schedule of halon, CFC, and HCFC production. Despite this production ban, emissions from black market generators and leaks from existing equipment and refrigerant stockpiles continue to warm the climate and are slowing the recovery of the Antarctic ozone hole[5,12]. The Kigali Amendment to the Montreal Protocol is designed to mitigate the climatic impact of HFC emissions by achieving an $80 \%$ reduction in HFC usage by 2047. Despite international pressure, industry backing, and bipartisan support, the U.S. Senate has not yet ratified the Kigali Amendment. Federal initiatives to reduce HFC use have also been weakened by recent court rulings and agency actions. In 2017, Obama-era restrictions on HFC use in major industrial sectors like mobile air conditioning and food retail were vacated[13]. Further, the Trump EPA has announced intentions to repeal Clean Air Act regulations prohibiting the venting of HFCs during equipment repair and disposal[14]. Despite federal inaction, 23 states have ratified legislation or are considering regulations to phase out HFC use and adopt alternative refrigerants like HFOs[15]. Uncertainty in the trajectory of federal and state regulations hinders the efforts of industry, institutions, and local governments to reduce their halocarbon refrigerant use and emissions.

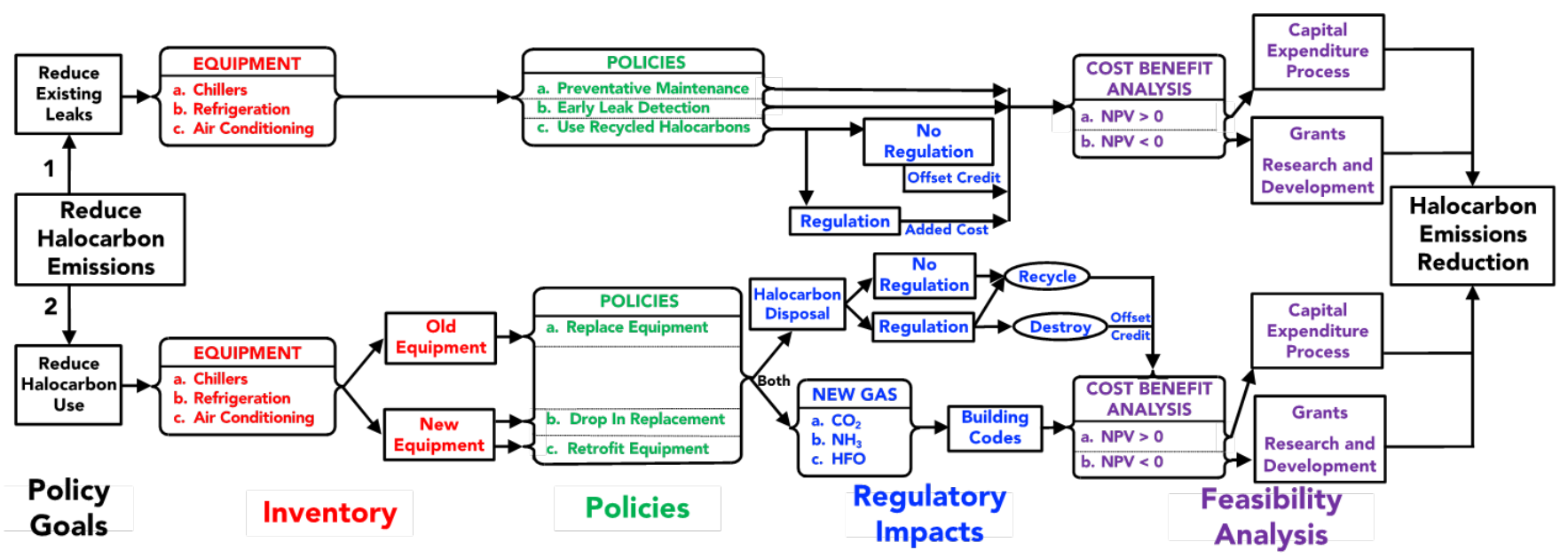

Figure 1: Pathways to Reduce Halocarbon Emissions. Policies can focus on two pathways to reduce halocarbon emissions: (1) managing and reducing leaks in existing equipment, and (2) reducing halocarbon use. Regulations can mandate or incentivize mitigating environmental damage. Offset credits can supplement or replace some regulations. For instance, institutions can claim offsets if using recycled refrigerants is not mandated. If regulations ban production of new gas, institutions can claim offset credits by destroying the refrigerant upon disposal. To finance greener infrastructure, institutional capital expenditure processes can fund projects with a calculated positive net present value (NPV), while grants for research and development of pilot projects can support initiatives with negative net present values. 


\section{Opportunities from Halocarbon Refrigerant Policy}

In the absence of federal regulations, state and local governments and institutions enjoy broad discretion to decide how best to reduce halocarbon refrigerant use and emissions. Policies that incentivize even voluntary reductions will yield environmental, educational, and financial benefits to institutions that mitigate their halocarbon refrigerant emissions. Academic institutions can claim moral leadership and inform students on best practices to quantify and reduce their environmental footprints. Industry can create new markets for alternative refrigerants. Corporations can improve their public image, reduce their negative externalities, and raise awareness of their corporate values by enhancing their efforts to reduce halocarbon refrigerant use and emissions. Finally, state and local governments can tailor policy to reduce halocarbon refrigerant emissions on timeframes that make sense financially and environmentally for their constituents.

As discussed below, there are important social, technical, financial, and public health challenges associated with these policies. Yet the factors behind these challenges are also the key to benefits behind policies to reduce halocarbon refrigerant emissions. There are technical obstacles; but also opportunities for innovation and the development of new businesses. There is regulatory uncertainty; but also the chance to shape impending regulation. Policies may be cost ineffective in the short term; but governments and institutions can define a new standard of environmentalism driven by stewardship and proactivity rather than immediate financial gain. To maximize each of these potential benefits, we outline the best practices, regulations, and voluntary institutional commitments that can be adopted to reduce halocarbon refrigerant emissions. These include steps to reduce leaks and phase out halocarbon refrigerant use by adopting replacements with lesser environmental impacts.

\section{Best Practices for Reducing Halocarbon Refrigerant Use and Emissions}

Governments and institutions can adopt three broad policies to reduce their halocarbon refrigerant use and emissions. The first is to compile data on halocarbon use and emissions. These inventories can then aid the management, and eventual phaseout, of halocarbon use in refrigerant-containing infrastructure.

\section{Compiling Inventories}

Institutions and regulators can quantify the potential environmental impact of halocarbon refrigerant leaks by establishing better inventories of use and emissions (Figure 1). Tracking use will help institutions prioritize which refrigerant-containing equipment to retrofit or replace with alternatives to halocarbons. Tracking emissions will alert institutions to leak-prone units, which can then be more closely monitored. The most accurate method to measure halocarbon refrigerant emissions is with a mass balance method, wherein purchases, disposal, and service contracts to recharge equipment with halocarbons after leaks are centrally compiled. Some large-scale users may also benefit from blockchain-based inventories with decentralized and distributed efforts to promote recordkeeping.

Institutions currently inventory use and emissions for equipment containing greater than 50 pounds $(22.7 \mathrm{~kg})$ of halocarbons to comply with Clean Air Act regulations[16]. However, users are not required to track equipment containing less than 50 pounds of halocarbons. Omitting these smaller units from inventories frustrates policies to reduce halocarbon refrigerant emissions. It is more difficult to detect leaks from smaller units, meaning many refrigerant emissions will be unnoticed and untracked. Further, smaller units usually have shorter lifetimes than larger units. Since the majority of halocarbon refrigerant emissions occur at the end of equipment life[10,11], smaller units may unknowingly constitute a majority of an institution's emissions. Finally, technological innovations have led to replacement options that greatly reduce or eliminate the use of halocarbons in smaller refrigeration and cooling units. An inventory including all refrigerant-containing equipment gives institutions and policymakers a complete understanding of the magnitude of emissions and can inform initiatives that would yield the greatest emissions reductions.

\section{Managing Halocarbon Refrigerant Use}

Governments and institutions can utilize these inventories to ensure halocarbon refrigerants are used responsibly. Emissions inventories will alert users to problematic products and designs, which may be addressed with retrofits or preventative maintenance. For instance, extant inventories indicate rubber gaskets on ultra-low temperature systems degrade more rapidly than standard units, and should be replaced before failure through preventative maintenance[17]. Further, emissions inventories will help institutions invest in leak detection systems where they are most needed. Embedded leak detection systems can automatically shut down systems and alert facilities when leaks occur, thereby preventing damage to equipment and minimizing halocarbon refrigerant emissions.

When leaks do occur, replacing halocarbons with reclaimed refrigerant rather than newly produced refrigerants minimizes environmental impact. While the production of CFCs and many HCFCs has been phased out, black market production of these refrigerants as well as legal production of HFCs continues[18]. Both the production and destruction of refrigerants are energy intensive processes with several toxic byproducts[19]. Requesting that repairs use purified recycled refrigerant avoids emissions associated with using virgin refrigerant and prevents the pollution resulting from refrigerant destruction. In the same vein, policies should incentivize the recycling of refrigerants while production is permitted and require the destruction of refrigerants when production is outlawed. This may force the market toward modern and environmentally-friendly refrigerant replacements instead of propping up older, inefficient cooling infrastructure.

\section{Reducing Halocarbon Refrigerant Use}

Finally, policies should recognize that minimizing 
halocarbon refrigerant use is requisite to reducing emissions. Reducing CFC and HCFC use in large applications will decrease the size of stockpiles and could avert up to 9 billion tons of equivalent $\mathrm{CO} 2$ emissions[5]. Institutions can begin by implementing pilot projects that demonstrate the benefits of and opportunities for adopting alternative refrigerants. One example is to perform drop-in replacements, wherein the same equipment is retrofitted with a more energy efficient halocarbon or an alternative refrigerant. Pilot projects provide an opportunity for institutions to gather data, disseminate knowledge, and enhance the visibility of their sustainability initiatives. As discussed below, such projects may also convince institutional management to support halocarbon refrigerant reduction policies by demonstrating the financial benefits using alternative refrigerants.

On longer timescales, institutions and governments should enact policies to phase out equipment using halocarbon refrigerants. Benchmarks include the reduction schedules outlined in the Montreal Protocol and Kigali Amendment, yet we note several governments - including California and the European Union - are pursuing more aggressive reductions[20,21]. These policies indicate that cooling infrastructure using halons, CFCs, and HCFCs should be retired imminently, while infrastructure using HFCs should be phased out within 30 years at maximum. To facilitate reducing halocarbon refrigerant use, policies could also incorporate language that prioritizes alternative refrigerants into capital planning documents, procurement contracts, and green building standards. Institutions consider many factors when purchasing new cooling equipment, such as cost, safety, ease of service, and preference for specific vendors. Including specific language about the environmental costs of using halocarbon refrigerants in planning documents, contracts, and standards will help institutions internalize the full impact of their choice of cooling infrastructure. Thorough cost benefit analyses can help users decide which equipment to replace and purchase. Relevant factors include energy efficiency, social costs of carbon, global warming potentials, and ease of construction due to building codes (Figure 1). Pilot projects that are not cost-effective may be funded through external grants for climate-friendly infrastructure.

\section{Challenges and Benefits of Halocarbon Refrigerant Policy}

Governments and institutions will need to address several social and technical obstacles to implement these policies. One challenge will be overcoming the expectation for, and benefits of, air-conditioned indoor spaces during longer summers and greater heat extremes[22, 23]. Ambient temperature not only affects comfort but also productivity and cognitive performance. For instance, students living in non-air-conditioned housing may perform worse on tests than students in climate-controlled housing[23]. This highlights equity issues that educational institutions and governments will encounter when reducing halocarbon refrigerant use. We emphasize that where cooling infrastructure is justified and beneficial, users can mitigate their environmental impact by applying greener technology with next-generation refrigerants.

Further, institutions and governments must contend with conflicting priorities and limited resources to address climate change. Several potential initiatives, such as preserving forests and constructing renewable energy infrastructure, are more charismatic climate solutions that will compete with issues like refrigerant use that are removed from the public eye. Despite the relative anonymity of halocarbon refrigerant use, policymakers should be aware of and publicize the enormous potential befits of scaling down their use. In fact, reducing halocarbon refrigerant emissions is the number one priority of Project Drawdown, a collection of solutions to cost-effectively reduce greenhouse gas emissions at scales sufficient to mitigate climate change[24].

Regulations and voluntary commitments to phase out halocarbon refrigerant use will also encounter technical challenges. For instance, alternative refrigerants are not universally viable in all applications and capacities. HFOs and some natural refrigerants, like propane and ammonia, are flammable and/or toxic. This may preclude their use in large centralized cooling infrastructure or near sensitive areas such as hospitals and schools until further technological developments resolve these issues. Further, the life expectancy of cooling equipment can be several decades. Any phase-out planning will need to consider that newer infrastructure is unlikely to be replaced in the near term, although simpler drop-in replacements may reduce the environmental impact of leaks until the equipment is retired.

Despite these challenges, there are several potential environmental and financial benefits to adopting alternatives to halocarbon refrigerants. One advantage is that institutions can cost-effectively reduce their greenhouse gas emissions by using alternatives. Several strategies, such as leak detection and drop-in retrofits, can halve the environmental impact of emissions while simultaneously reducing repair costs. While HFO units are generally less energy efficient than halocarbon systems, existing HFC drop-in replacements and natural refrigerants use up to $14 \%$ less energy than currently-used halocarbons to achieve the same cooling capacity[25, 26]. This reduces operating costs and can offset the higher capital costs of new halocarbon-free systems over the equipment lifetime. Reduced energy consumption also decreases an institution's greenhouse gas emissions. Institutions may also generate and sell carbon offset credits for reducing their halocarbon use and emissions. This includes efforts to detect and prevent refrigerant leaks, destroy CFCs and HCFCs, and use recycled HFCs in refilling equipment[27].

Financial and environmental benefits of reducing halocarbon refrigerant use and emissions can be achieved at all stages in the cooling infrastructure lifecycle. Policies that incentivize users to purchase equipment using alternative refrigerants can avoid decades of emissions while reducing energy consumption. As equipment is retired, institutions can destroy halocarbon refrigerants that are no longer being produced to gain carbon offset credits and force the market 
towards better refrigerant alternatives. While these efforts are environmentally beneficial at any scale, mitigating the worst impacts of refrigerant emissions will require widespread adoption of policies to reduce halocarbon refrigerant use.

\section{Acknowledgements}

The foundational research for this article was supported by Harvard University's Climate Solutions Living Lab. We are deeply grateful to the faculty, staff, and teaching fellows of the Lab for their insight into halocarbon policy design. We also thank the offices of Environmental Health and Safety and Facilities at Harvard and MIT for their feedback on our policies.

\section{Citation}

Wolf M. et al. Institutions and governments can slow climate change by regulating and reducing halocarbon refrigerant use. MIT Science Policy Review 1, 39-43 (2020).

\section{Open Access}

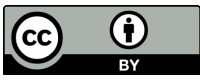

This MIT Science Policy Review article is licensed under a Creative Commons Attribution 4.0 International License, which permits use, sharing, adaptation, distribution and reproduction in any medium or format, as long as you give appropriate credit to the original author(s) and the source, provide a link to the Creative Commons license, and indicate if changes were made. The images or other third party material in this article are included in the article's Creative Commons license, unless indicated otherwise in a credit line to the material. If material is not included in the article's Creative Commons license and your intended use is not permitted by statutory regulation or exceeds the permitted use, you will need to obtain permission directly from the copyright holder. To view a copy of this license, visit http://creativecommons.org/licenses/ by $/ 4.0 /$.

\section{References}

[1] Molina, M. \& Rowland, F. Stratospheric sink for chlorofluoromethanes: chlorine atom-catalysed destruction of ozone. Nature 249, 810-812 (1974). https: //doi.org/10.1038/249810a0.

[2] Henriksen, T., Dahlback, A., Larsen, S. H. H. \& Moan, J. Ultraviolet-radiation and skin cancer. Effect of an ozone layer depletion. Photochemistry and Photobiology 51, 579-582 (1990). https://doi.org/10.1111/j.1751-1097.1990. tb01968.x.

[3] IPCC AR5. Anthropogenic and Natural Radiative Forcing. In: Climate Change 2013: The Physical Science Basis. Contribution of Working Group I to the Fifth Assessment Report of the Intergovernmental Panel on Climate Change. Tech. Rep. (2013).

[4] Velders, G. J. M., Solomon, S. \& Daniel, J. S. Growth of climate change commitments from HFC banks and emissions. Atmospheric Chemistry and Physics 14, 4563-4572 (2014). https://doi.org/10.5194/acp-14-4563-2014.

[5] Lickley, M. et al. Quantifying contributions of chlorofluorocarbon banks to emissions and impacts on the ozone layer and climate. Nature Communications 11, 1-11 (2020). https://doi.org/ $10.1038 / \mathrm{s} 41467-020-15162-7$.

[6] Montzka, S. A. et al. An unexpected and persistent increase in global emissions of ozone-depleting CFC-11. Nature 557, 413-417 (2018). https: //doi.org/10.1038/s41586018-0106-2.
[7] Xu, Y., Zaelke, D., Velders, G. J. M. \& Ramanathan, V. The role of HFCs in mitigating 21st century climate change. Atmospheric Chemistry and Physics 13, 6083-6089 (2013). https: // doi. org/10.5194/acp-13-6083-2013.

[8] Hu, A., Xu, Y., Tebaldi, C., Washington, W. M. \& Ramanathan, V. Mitigation of short-lived climate pollutants slows sea-level rise. Nature Climate Change 3, 730-734 (2013). https: //doi.org/10.1038/nclimate1869.

[9] Zickfeld, K., Solomon, S. \& Gilford, D. M. Centuries of thermal sea-level rise due to anthropogenic emissions of short-lived greenhouse gases. Proceedings of the National Academy of Sciences 114, 657-662 (2017). https: / / doi .org/10.1073/ pnas. 1612066114 .

[10] Palandre, L., Zoughaib, A., Clodic, D. \& Kuijpers, L. Estimation of the world-wide fleets of refrigerating and air-conditioning equipment in order to determine forecasts of refrigerant emissions. In Proceedings of the 14th Annual Earth Technologies Forum (2013).

[11] EPA 430-R-18-001, ICF International, Destruction of Ozone-Depleting Substances in the United States (2010).

[12] Dhomse, S. S. et al. Delay in recovery of the Antarctic ozone hole from unexpected CFC-11 emissions. Nature Communications 10 (2019). https://doi.org/10.1038/s41467-019-13717-

[13] Mexichem Fluor, Inc. v. EPA, 866 F.3d 451456 (2017).

[14] 83-FR-49332, Protection of Stratospheric Ozone: Revisions to the Refrigerant Management Program's Extension to Substitutes. Federal Register (2018)

[15] Doniger, D. \& Theodoridi, C. More States Announce HFC Action, Raising Tally to Fifteen. Available at https://www.nrdc. org/experts/david-doniger/more-states-announcehfC-action-raising-tally-fifteen (2020/02/18).

[16] 40 CFR Part 82, Subpart F

[17] Calm, J. M. Emissions and environmental impacts from air-conditioning and refrigeration systems. International Journal of Refrigeration 25, 293-305 (2002). https:// doi .org/10. 1016/S0140-7007(01)00067-6.

[18] U.S. EPA. ODS Destruction in the United States and Abroad Tech. Rep. (2018).

[19] Jones, B. et al. Future population exposure to US heat extremes. Nature Climate Change 5, 652-655 (2015). https://doi. org/10.1038/nclimate2631.

[20] California Cooling Act SB 1013 (2018).

[21] European Council Regulation No 842/2006 on Certain Fluorinated Greenhouse Gases. Official Journal of the European Union (2006).

[22] Xu, Y. et al. Substantial Increase in the Joint Occurrence and Human Exposure of Heatwave and High-PM Hazards Over South Asia in the Mid-21st Century. AGU Advances 1 (2020). https://doi.org/10.1029/2019AV000103.

[23] Laurent, J. G. C. et al. Reduced cognitive function during a heat wave among residents of non-air-conditioned buildings: An observational study of young adults in the summer of 2016 . PLOS Medicine 15 (2018). https://doi.org/10.1371/ journal.pmed.1002605.

[24] Hawken, P. Drawdown: The most comprehensive plan ever proposed to reverse global warming (Penguin, 2017).

[25] Oruç, V., Devecioğlu, A. G. \& Ender, S. Improvement of energy parameters using R442A and R453A in a refrigeration system operating with R404A. Applied Thermal Engineering 129 (2018). https://doi.org/10.1016/j.applthermaleng. 2017.10 .035 .

[26] Gil, B. \& Kasperski, J. Efficiency evaluation of the ejector cooling cycle using a new generation of HFO/HCFO refrigerant as a R134a replacement. Energies 11 (2018). https://doi.org/ $10.3390 /$ en 11082136.

[27] Registry, A. C. Methodology for the quantification, monitoring reporting and verification of greenhouse gas emissions reductions and removals from advanced refrigeration systems, version 2.0 (2018). 